\title{
AN EVALUATION OF THE HYPOTHESIS OF SHIFTING TERMINALS IN GOLDFISH OPTIC TECTUM ${ }^{1}$
}

\author{
STEPHEN S. EASTER, JR.,2 AND CLAUDIA A. O. STUERMER ${ }^{3}$ \\ Division of Biological Sciences, University of Michigan, Ann Arbor, Michigan 48109
}

Reccived August 24, 1983; Reviscd October 26, 1983; Accepted October 27, 1983

\begin{abstract}
It has been proposed that the terminal arbors of retinal ganglion cells continually shift positions in the optic tectum as a natural consequence of growth in larval amphibians and teleost fish. Here, we develop a detailed anatomical model of this process, based on recent observations in goldfish. The model predicts some unusual structural features of optic axons in the tectum. It was tested in two ways by use of the tracer, horseradish peroxidase (HRP).

In the first, optic axons in the tectum were visualized by anterogradely transported HRP applied in the nerve or retina. As predicted, the axons had three parts: (1) fascicular segment (in the stratum opticum), (2) extrafascicular segment (in the synaptic neuropil), and (3) terminal arbor (also in the neuropil). The extrafascicular segment extended up to $1 \mathrm{~mm}$ caudally from the fascicle through which it entered the tectum. At its terminus, the arbor was restricted to a single lamina in which it branched extensively over an elliptical area with major axes between 100 and $200 \mu \mathrm{m}$ long.

In the second test, retinal ganglion cell bodies were labeled by retrogradely transported HRP applied to the tectum in a manner intended to label all axons and terminals in the vicinity. The pattern and locations of labeled cells varied, depending on where the HRP was applied, in detailed accord with the model's predictions.

The close agreement between the model and the observations supports the hypothesis of shifting terminals.
\end{abstract}

Gaze and his collaborators first pointed out that the retina and tectum of Xenopus laevis grow in topologically dissimilar patterns. The retina adds cells all the way round its edge, in an anulus (Straznicky and Gaze, 1971), whereas the tectum grows along a more linear front, adding wedges of cells to the caudomedial boundary of the tectum (Straznicky and Gaze, 1972). This incongruity is important because the projection of the retina onto the tectum is qualitatively similar in animals of all ages (Gaze et al., 1974), which seems to require that the terminal arbors of the retinal ganglion cells must continually move about on the tectum to maintain retinotopia.

This "hypothesis of sliding connections" met with considerable skepticism, and Jacobson challenged the

\footnotetext{
${ }^{1}$ We thank Messrs. Joseph Fetcho, Bradford Bratton, and David Bay for technical assistance, and Drs. P. Raymond, P. Hitchcock, and Mr. S. Scherer for useful comments on the paper. This work was supported by National Eye Institute of the National Institutes of Health Grant EY-00168 to S. S. E. and Deutsch Forschungsgemeinschaft Grant DFG Stu 112 to C. A. O. S.

${ }^{2}$ To whom correspondence should be addressed, at the Salk Institute for Biological Studies, P. O. Box 85800, San Diego, CA 92138.

"Current address: Max Planck Institut fur Virusforschung, Abt. Physikalische Biologie, Spemannst. 34, D7400 Tubingen, West Germany.
}

interpretation with new experiments. In the first (Jacobson, 1976), he showed that retinal growth was very asymmetric in late-stage Xenopus tadpoles. There were so few cells added dorsally that the anulus could be approximated by a C-shaped contour, open dorsally. If growth occurred along a similarly shaped open contour in tectum, then it would be possible in principle to maintain all of the earlier synaptic connections (formed between retinal and tectal cells inside the C's) while adding new tectal tissue in topologically corresponding places (outside the C's) and forming new connections there. Jacobson's data on the asymmetry of retinal growth were confirmed by Gaze et al. (1979), but his argument foundered because the nearly open part of the retinal growth zone and the clearly open part in the tectal growth zone were not in topographically corresponding positions (Gaze et al., 1979).

In a second experiment, Jacobson attempted to assess the movement of terminals by injecting radioactive thymidine systemically, to mark the tectal growth zone, and radioactive amino acid intraocularly, to label the tectal terminals of the ganglion cells present at the time of injection. The animals were allowed to survive for an interval during which the terminals could move, and then the brains were sectioned and autoradiographed. If 
terminals had shifted, then radioactive grains should have been found in the neuropil of "new" tectum, caudal and medial to the cells with labeled nuclei. The results were equivocal and were interpreted as evidence against the hypothesis (Jacobson, 1977). A similar experiment, with similar results, had been reported by Scott and Lázár (1976), but it was interpreted as evidence in support of movement. A more thorough attempt with this same method gave stronger support (Gaze et al., 1979). Recently, Reh and Constantine-Paton (1984) have improved the resolution of this kind of experiment by labeling (with HRP) the terminals of only the most central retinal ganglion cells in Rana pipiens, and they demonstrated clearly that the terminals do shift. A rather different experimental approach led Fraser (1983) to the same conclusion in Xenopus.

All of the shifts in amphibians occur over a relatively few weeks in larval life when both retina and tectum are growing. After metamorphosis, the retina continues to grow slowly, but the tectum stops growing (Straznicky and Gaze, 1971, 1972; Hoskins and Grobstein, 1982). In fish, both retina and tectum continue to grow for many years (Müller, 1952; Kirsche, 1967; Johns and Easter, 1977). In goldfish, the topological dissimilarity of the growth zones is as striking as in amphibians: the retina adds anuli, the tectum, crescents (Meyer, 1978; Raymond and Easter, 1983). Yet the retinotectal projection is qualitatively similar in both small (Meyer, 1977) and large (Schmidt et al., 1978) goldfish. Therefore, the connections are likely to shift naturally in this species as well, as Meyer (1978) suggested.

We offer, first, a model of the events involved in the establishment and maintenance of the retinotectal projection in goldfish. Then, after the methods have been outlined, we describe the results of experiments explicitly designed to test the model, and we relate them to the model. Preliminary accounts have been presented elsewhere in abstracts (Easter and Stuermer, 1982, 1983; Stuermer and Easter, 1983).

\section{The Model}

We make four assumptions, all based on observations.

1. The retina adds new ganglion cells appositionally, in anuli around the retinal margin (Müller, 1952; Johns, 1977; Meyer, 1978).

2. The tectum adds new neurons appositionally, along a C-shaped contour, with the rostral side open. The new cells occupy a crescent, thickest caudally, with arms attenuated rostrally on the dorsal and ventral rims (Meyer, 1978; Raymond and Easter, 1983).

3. The retinal axons in the stratum opticum (SO) of tectum are ordered as described by Stuermer and Easter $(1982,1984)$. Ventral and dorsal hemiretinas serve dorsal and ventral hemitecta, respectively. The fascicles form a fan-like array (Figs. 3 and 4 ); the short central fascicles which terminate more rostrally are the older, and the longer peripheral ones which end more caudally are the younger. Each fascicle contains axons from ganglion cells restricted to a half anulus in the retina, and the fascicle defines the outer boundary of the tectum at the time its axons grew in. The axons within each fascicle exit in order, the ones from most temporal retina first (in rostral tectum) and those from nasal retina last (caudally). The axons initially terminate near their site of exit.

4. The retinal ganglion cells terminate retinotopically on tectum at all times (Meyer, 1977; Schmidt et al., 1978).

In the model described below, the three-dimensional (roughly hemispheric) retinal and tectal surfaces are shown in two dimensions. Although this distorts the geometry, it does not affect the qualitative aspects of the predictions.

Figure 1 illustrates the model. It shows the right ventral hemiretina, with three generations of ganglion cells indicated by the stippled zones. The distance from the center is an indication of youth: $R A$ is older than $R B$ is older than $R C$. In Figure 1a, the left dorsal hemitectum is shown, onto which the hemiretina in Figure $1 b$ projects. The three stippled zones, $T A, T B$, and $T C$, show the retinotopic locations of the terminals of the ganglion cells in $R A, R B$, and $R C$, respectively. The temporonasal direction on the retina maps onto the rostrocaudal direction in the tectum. The drawings are oriented so that if the bottom of the hemitectum is apposed to the top of the hemiretina, then the topographic mapping is symmetric across this common boundary.

The axons that terminate in $T A, T B$, and $T C$ enter the tectum in the fascicles shown by solid lines labeled $\alpha, \beta$, and $\gamma$, respectively. $\gamma$, the most recently formed, lies at the outer boundary of the tectum, and its terminal zone, $T C$, is adjacent. $T B$ is slightly displaced from $\beta$, and $T A$ is a long distance from $\alpha$. These separations show the shift of terminals which occurred between the times when the axons in $\alpha$ and $\beta$ first grew in and the present time. By assumption, the axons initially terminated near their fascicles, but as the retina and tectum grew, the terminals gradually shifted toward their present sites. Therefore, they must be connected to their fascicles, as shown in Figure 3 of the preceding paper (Stuermer and Easter, 1984).

These extrafascicular segments are very important to the model, as they pass through the regions where an axon once terminated, on its way from the original termination site to the current one. All of our predictions involve this portion of the axon, which had not previously been thought to exist (see the "Discussion").

Now consider the two ganglion cells at the nasal and temporal extremities of $R A$. Both of their axons originally entered tectum through the fascicle, $\alpha$. The axon from the nasal end of $R A$ exited at $\alpha$ 's caudal end to terminate nearby (arrow labeled $I$ ). As new tectum was added, this terminal shifted along the border between dorsal and ventral hemitecta (hereafter called the equator) and is now at the caudal end of TA. The axon from the cell body at the temporal end of $R A$ originally exited the fascicle, $\alpha$, at its extreme rostral end and, over the years, shifted toward its current termination site at the rostral end of TA. Clearly, there is a little region, indicated by a bracket, where the two extrafascicular axons (dashed lines) run together. Equally clearly, there must be other extrafascicular axons in this region which originated from those retinal cell bodies along the horizontal line connecting the two ends of $R A$. Axons from all of these cells originally entered the tectum in fascicles closer to the equator than the fascicle $\alpha$, and all of them 


\section{a. DORSAL LEFT HEMITECTUM}
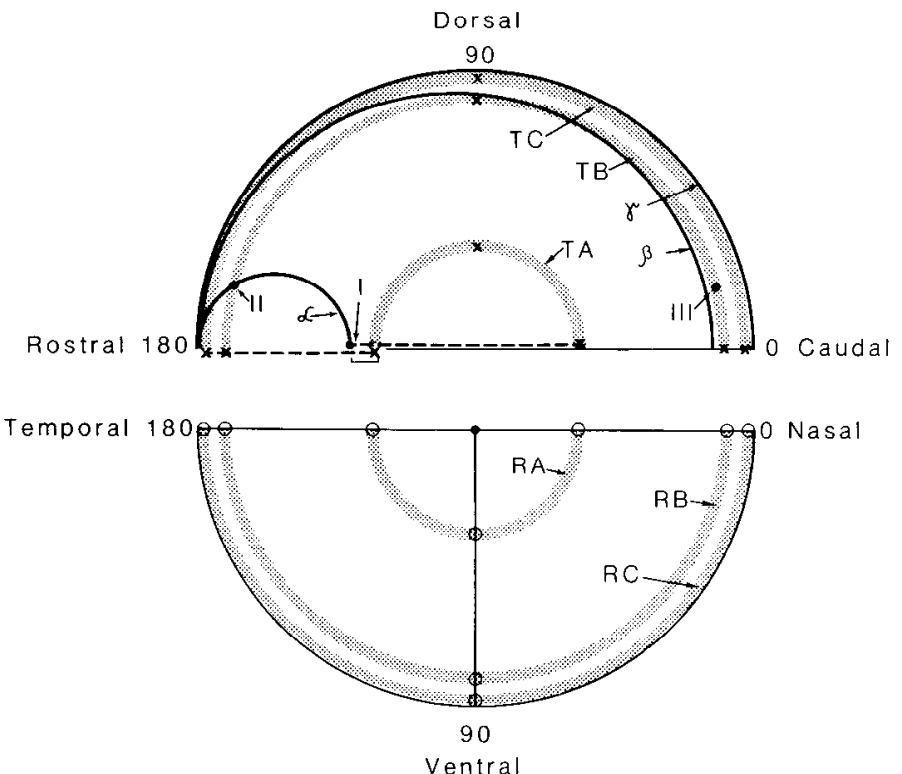

b. VENTRAL RIGHT HEMIRETINA c. SITE I

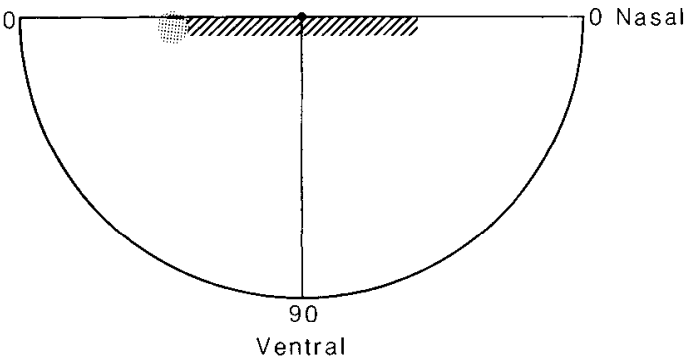

d. SITE II
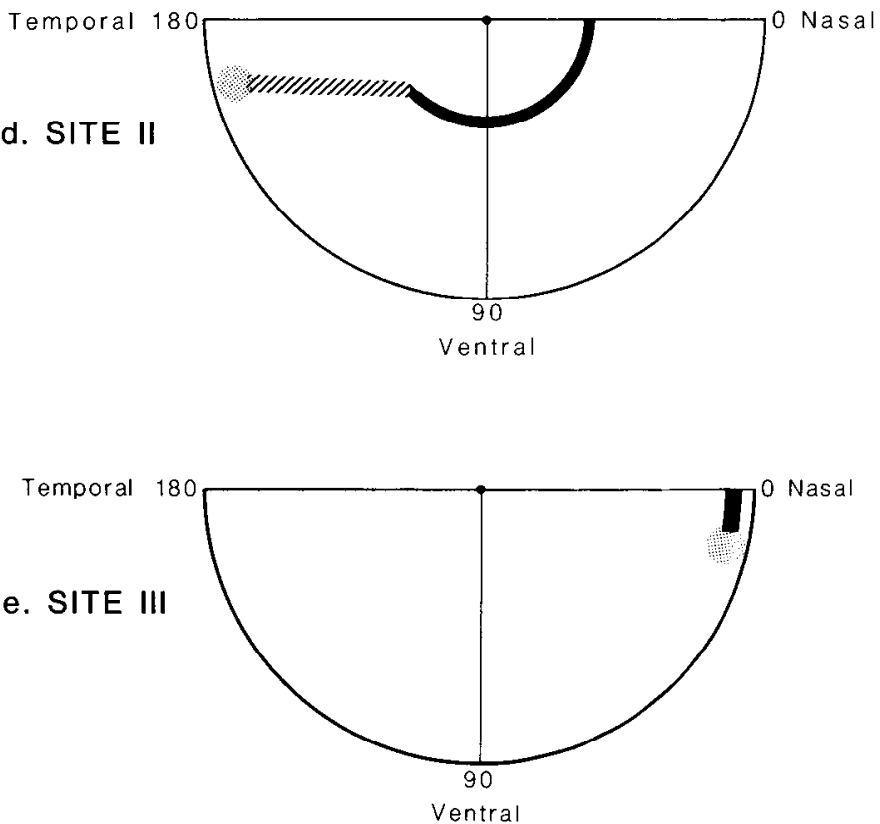

Figure 1. A schematic view of the model of shifting terminals, with predictions for patterns of retrograde labeling in the retina. $a$, The solid lines, $\alpha, \beta$, and $\gamma$ show three fascicles of optic fibers which terminate, respectively, in the zones $T A, T B$, and $T C$, indicated by the stippling. The $x$ 's indicate termination sites of nine particular cells (see $b$ ). $I, I I$, and $I I I$ are three sites at which label (HRP) is predicted to produce the patterns shown in $c, d$, and $e$, respectively. $b$, The stippling shows three half anuli, $R A$, $R B$, and $R C$, from which the ganglion cells enter tectum through $\alpha, \beta$, and $\gamma$ and terminate in $T A, T B$, and $T C$, respectively. The nine small circles indicate particular ganglion cells which terminate at the symmetrically positioned $x$ 's in $a$. $c, d$, and $e$, Three patterns of retrogradely labeled cells that are predicted to follow application of HRP to sites $I, I I$, and $I I I$ in $a$. Solid black, fascicular zone; diagonal lines, extrafascicular zone; stippling, terminal zone.

now project to sites along the horizontal line which connects the two ends of $T A$. Therefore, on the rostral part of the equator, there will be many extrafascicular axons of passage in addition to the axon terminals which we associate with the retinotectal map. This same argument applies elsewhere, too. In general, underneath any site on the tectal surface, there will be axons in fascicles in SO, extrafascicular axons deep to SO, and axon terminals.

\section{Predictions}

There are two classes of predictions from this model. One relates to the anatomy of the intratectal retinal axons and the other to the retinal locations of cells with axons or terminals at any site in tectum. Both predictions are tested anatomically.

The retinal axons, visualized with anterogradely transported HRP, should have the following features. The terminal arbor may be a variable distance from the fascicle through which the axon entered the tectum. The fascicular segment should be linked to the terminal arbor through an extrafascicular segment. Since this segment is the remnant of the continually shifting terminal, the axon should lie in the synaptic zone deep to SO. The orientation of the extrafascicular segment will depend on its location. Near the equator, it will be oriented rostrocaudally. Off the equator, it will point obliquely. The longest extrafascicular segments should be those originating in rostral tectum and extending caudally.

To determine which ganglion cells have terminals or axons at any tectal site (i.e., passing through a column perpendicular to the tectal surface), we labeled such a column with HRP and then examined the contralateral retina for retrogradely labeled cells.

Consider, for example, the site labeled $I I$ in Figure $1 a$, at the intersection of fascicle $\alpha$ and terminal zone $T B$. At this point, about one-fourth of the axons in $\alpha$ have already exited, and about three-fourths remain. The re- 
maining axons are the ones that terminate in the caudal three-fourths of the terminal zone $T A$ and, therefore, originate from the partial half anulus shown by the black contour in Figure $1 d$. If HRP were given at site $I I$, therefore, we would predict that the cells in that region would be labeled through the fascicular portions of their axons. Site $I I$ is retinotopically related to the circular stippled region in Figure $1 d$. Therefore, we predict that the cells in that region of the retina would be labeled through their terminals. Finally, all of those retinal cells that once terminated at $I I$ but now terminate elsewhere will have extrafascicular axons passing through II. The first ones to have terminated there, after the departure of the initial terminals from $R A$, would have been from cells slightly peripheral to the initial inhabitants. The cells that most recently terminated at $I I$, just prior to the arrival of the current occupants, are just central to the cells that currently terminate there. Similar arguments based on continuity of the shifts lead to the conclusion that the cells with their extrafascicular segments passing through $I I$ must have originated from a zone linking the temporal end of the partial anulus to the patch of terminally labeled cells. This region is indicated by the diagonal lines. (We schematize it as a straight line, but this is only an approximation. Its exact orientation and curvature depend on quantitative details of retinotectal growth which we cannot specify.)

Note that this sickle-shaped zone has three distinct regions: a blade, a handle, and a bulbous end of the handle. They correspond to the three parts of the axons through which the cells were labeled. Hereafter, they are referred to as the fascicular, extrafascicular, and terminal zones, respectively.

Consider now site $I I I$, symmetrically positioned across the vertical midline from site $I I$. It intersects the extreme caudal portion of a very peripheral fascicle (not shown) between $\beta$ and $\gamma$, and so its fascicular retinal zone is expected to be a very short portion of a very peripheral anulus, the black region in Figure 1e. The terminal zone is tectotopically related to $I I I$ and is shown by the stippled area in Figure 1e. The extrafascicular segments in very peripheral tectum are, by hypothesis, quite short, because this is the youngest part of the tectum, where the terminals have not shifted much from the initial site of entry. Therefore, we predict that the extrafascicular zone will be very small and probably indistinguishable from the other two after labeling at III.

Finally, consider the case of site $I$, right on the tectal equator, at the caudal end of the fascicle $\alpha$. Very few axons still remain in the fascicle here, so we predict that no fascicular zone would be evident. The terminal zone is shown by the stippled region of Figure $1 c$. The extrafascicular zone includes those cells along the horizontal line linking the nasal end of the contour, $R A$, to the terminal zone (diagonal lines in Figure 1c).

The pattern in Figure $1 d$ is the most general one, because it includes distinctive subdivisions corresponding to the cells labeled in each of the three axonal segments. Various aspects of these three zones are predicted by the model. The fascicular zone is a portion of a half anulus that abuts the boundary between dorsal and ventral hemiretinas on the nasal side and extends a variable distance toward the temporal side. Its distance from the optic disk is predictable from a knowledge of which fascicle was labeled. The more rostral the fascicle, the more central the anulus. The angular subtense of the partial anulus with respect to the disk depends upon where the fascicle was labeled. The more rostral the label, the larger the angular subtense. The extrafascicular zone indicates by its length the maximum length of the extrafascicular segments passing through the label site. The terminal zone is the most straightforward and conventional, because it corresponds tectotopically to the label site.

\section{Materials and Methods}

The maintenance and care of the fish were described in the preceding paper (Stuermer and Easter, 1984). To label retinal axons and terminals in the tectum, HRP was applied to either the retina or the optic nerve. For retinal applications, the cornea and lens were removed surgically, a group of axons was cut near the optic disk, and a crystal of HRP was placed at the cut. The lens and cornea were then returned, and the fish was revived. The nerve was labeled intraorbitally by cutting a small fraction of the axons and then inserting a crystal of HRP near the cut ends. Several ( 2 to 4) days later the fish was anesthetized, perfused with saline, and the tectal lobes were cut away from the brain and reacted whole for HRP (Fujisawa et al., 1981), using diaminobenzidine as the chromogen. The tectal lobes were partially bisected along the equator, gently flattened under lens paper, and fixed in buffered glutaraldehyde. Then they were dehydrated through graded ethanols, cleared in xylene, mounted on a microscope slide in Permount, and coverslipped. Intraretinal labeling allowed us to select which cells were labeled but produced relatively weakly labeled tectal terminals. Labeling in the nerve did not permit a choice of cells, but the tectal terminals were more heavily labeled.

To label the tectum, a portion of the dorsal cranium was removed and the superficial fatty material was aspirated away. A micropipette, broken at the tip, was poked into the tectum to form a hole 50 to $100 \mu \mathrm{m}$ wide and extending through to the ventricle. Then a crystal of HRP was inserted into the hole, the cranium was resealed, and the fish was revived. Several days later, the retina was whole-mounted and reacted for HRP as described in the preceding paper (Stuermer and Easter, 1984). In some cases, the hyaloid blood vessels on the vitreal surface were also removed to make the retina more photogenic (e.g., Fig. 5). Generally this was not done, as the labeled ganglion cell bodies were easily distinguished from the vasculature in the microscope because they lay at a different level.

Following tectal insertion of HRP, the tectum was also reacted for HRP, but without perfusion. The presence of blood cells in the tectum precluded any detailed observations there, because red blood cells stained heavily in the HRP processing. But the location of the HRP insertion was readily determined from both the hole and the presence of a halo of HRP reaction product. 


\section{Results}

Visualization of intratectal retinal axons. When a small fraction (thousands) of retinal axons was labeled, either in the retina or in the nerve, individual axons could often be traced in the tectum. They entered through one of the fascicles in SO (Fig. $2 a$ ) and at some point left the fascicle to dip a few tens of micrometers deeper into tectum, then coursed a variable distance before terminating. Usually, such axons remained unbranched until the terminus. Figure $2 b$ shows a photomicrograph of the transition from axon to terminal arbor. The axon became thicker at this point and divided immediately into two major branches, which then subdivided.

Owing to the limited depth of field in the compound microscope, it is not possible to demonstrate photographically more extended views of the labeled axons. They are best conveyed in camera lucida drawings, such as the ones in Figure 3. A low-magnification view of the tectal whole mount following a partial label of the nerve is seen in Figure 3a. Only the labeled fascicles are shown here; the labeled extrafascicular axons and terminals have been omitted. Only a few of the fascicles were labeled, mostly in dorsal hemitectum. The region contained in the dashed rectangle is shown at a higher magnification in Figure $3 b$, which is a partially complete drawing which shows the labeled axons at two depths. To the left, the fascicles in SO are seen coursing downward and to the right. Issuing from these fascicles are a large number of extrafascicular axons, much too numerous to sketch individually, but quite uniform in their directions, as shown. Those near the equator were parallel to it; those more dorsally situated coursed obliquely, toward the dorsal tectal rim. Their terminals lay in the right half of this field, roughly at the center of the tectum close to the equator. A few of the axons could be traced individually, because of their relatively dense and uninterrupted label and their relative isolation from other labeled processes. Two of these are shown in Figure 3c. The upper one originated from a fascicle not shown here. The fascicle of origin for the lower one is shown. Both of these extrafascicular segments have several features in common. They run a few tens of micrometers deep to the $\mathrm{SO}$, in the synaptic layers. They are about $1 \mathrm{~mm}$ long. They have spindle-shaped enlargements at intervals of 50 to $150 \mu \mathrm{m}$. They are essentially unbranched proximal to the terminal arbor. The terminal arbors are roughly elliptical, longer rostrocaudally than dorsoventrally, and

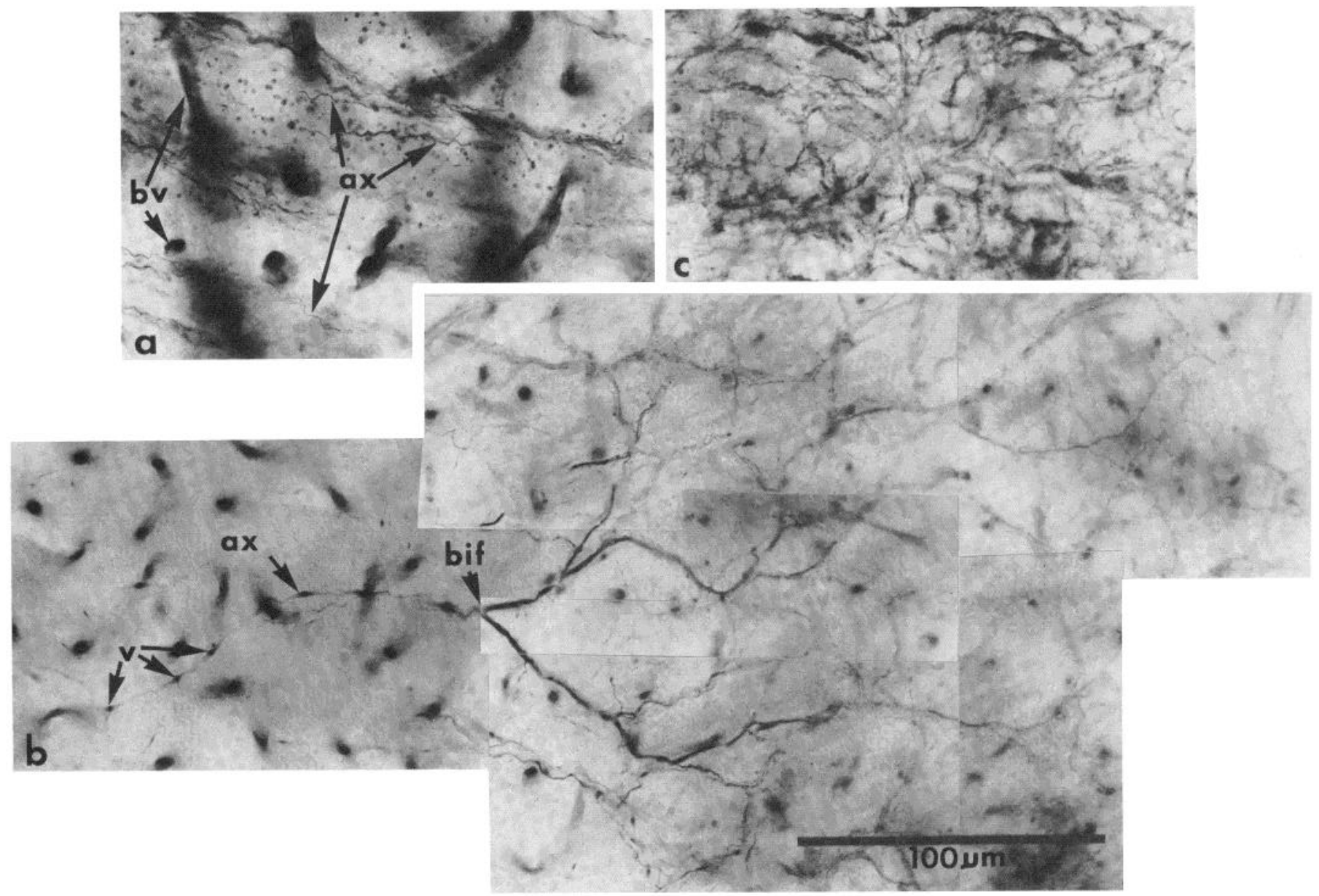

Figure 2. Light micrographs of HRP-processed tectal whole mount, following application of HRP to the optic nerve. $a$, Plane of focus in SO, showing the labeled axons $(a x)$ in fascicles. Blood vessels $(b v)$ stain heavily. $b$, Plane of focus in the synaptic layer, $50 \mu \mathrm{m}$ deeper than in $a$. One extrafascicular axon $(a x)$ is relatively isolated. It has periodic varicosities $(v)$, and it thickens in the vicinity of its major bifurcation (bif) before ramifying. $c$, In the same plane of focus as $b$ but about $100 \mu \mathrm{m}$ lateral. In this region, nearly all of the optic fiber arbors are labeled. 

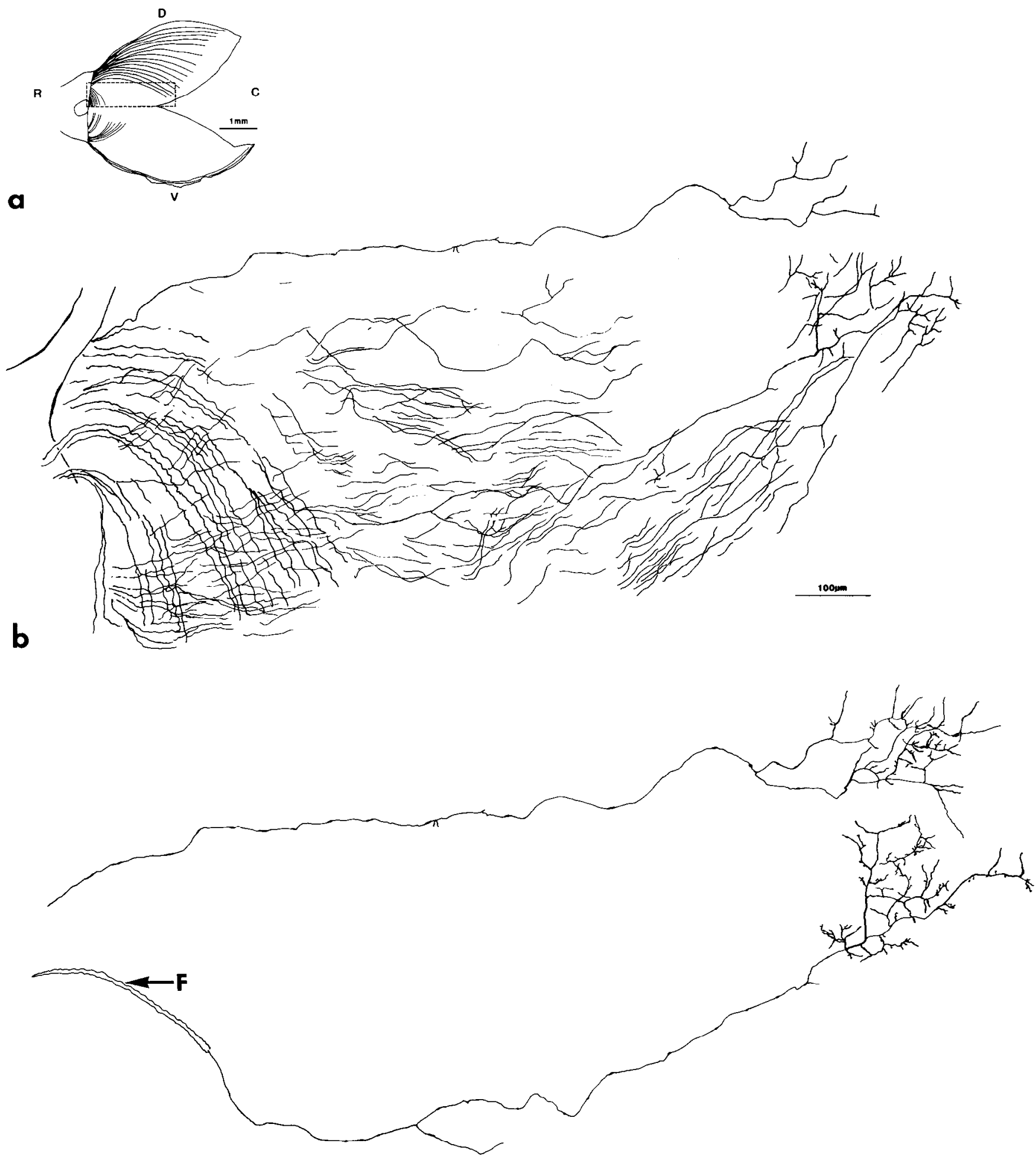

C

Figure 3. Camera lucida drawings of HRP-processed left tectal whole mount, following application of HRP to the optic nerve. $a$, Low-magnification sketch showing labeled fascicles. $R$, rostral; $D$, dorsal; $C$, caudal; $V$, ventral. The rectangle indicates the field shown in $b$ and $c . b$, The (superficial) fascicular axons are on the left side and coursc down and to the right. The (decp) extrafascicular axons course predominantly to the right and upward, terminating toward the right. $c$, Two axons and their terminals, from the field in $b$, drawn in detail. $F$, fascicle of origin. 
about 100 to $200 \mu \mathrm{m}$ across. A more detailed description of these terminals is currently in preparation by one of us (C. A. O. Stuermer).

To compare the lengths of the extrafascicular segments, it is necessary to label axons in many fascicles, extending from rostral to peripheral tectum. Intraretinal labeling accomplishes this. When a small bundle of axons was labeled in right ventronasal retina near the disk, the retinal whole mount confirmed that cells from nearly an entire sector were labeled (Fig. 4a). The left tectal whole mount is shown in Figure 4b. A small fraction of the axons in most fascicles of the dorsal hemitectum were labeled. Their terminals lay in a retinotopically positioned wedge in dorsocaudal tectum. Extrafascicular axons were traced from many of the fascicles to their terminal arbors. From the more rostral fascicles issued axons that ran a long distance parallel to the equator and terminated in the rostral part of the wedge. Progressively more peripheral fascicles contributed axons that coursed shorter distances and terminated more caudally.
Axons in the most peripheral fascicles terminated nearby, in caudal tectum, with scarcely any extrafascicular segment.

In summary, all of the predictions relating to the morphology of the intratectal retinal axons have been upheld.

Retrograde labeling of retinal ganglion cells. The model predicts that in any column perpendicular to the tectal surface, there will be fascicular axons, extrafascicular axons, and axon terminals. Prior to completion of the work described in the first section, there was no doubt of the presence of the fascicular and terminal portions. The data of Figures 2, 3, and 4 have confirmed the existence of extrafascicular segments as well (see also Cook et al., 1983). Now the model will be tested to learn how well it predicts where in the retina these various axons originate.

Our experimental method was to label the entire tectal depth with HRP, expecting that fascicular, extrafascicular, and terminal portions would all incorporate the

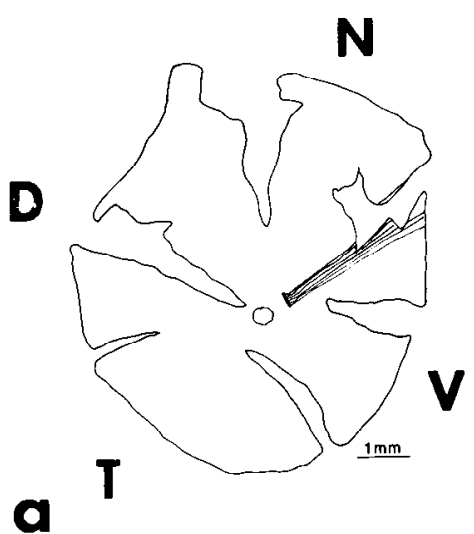

D

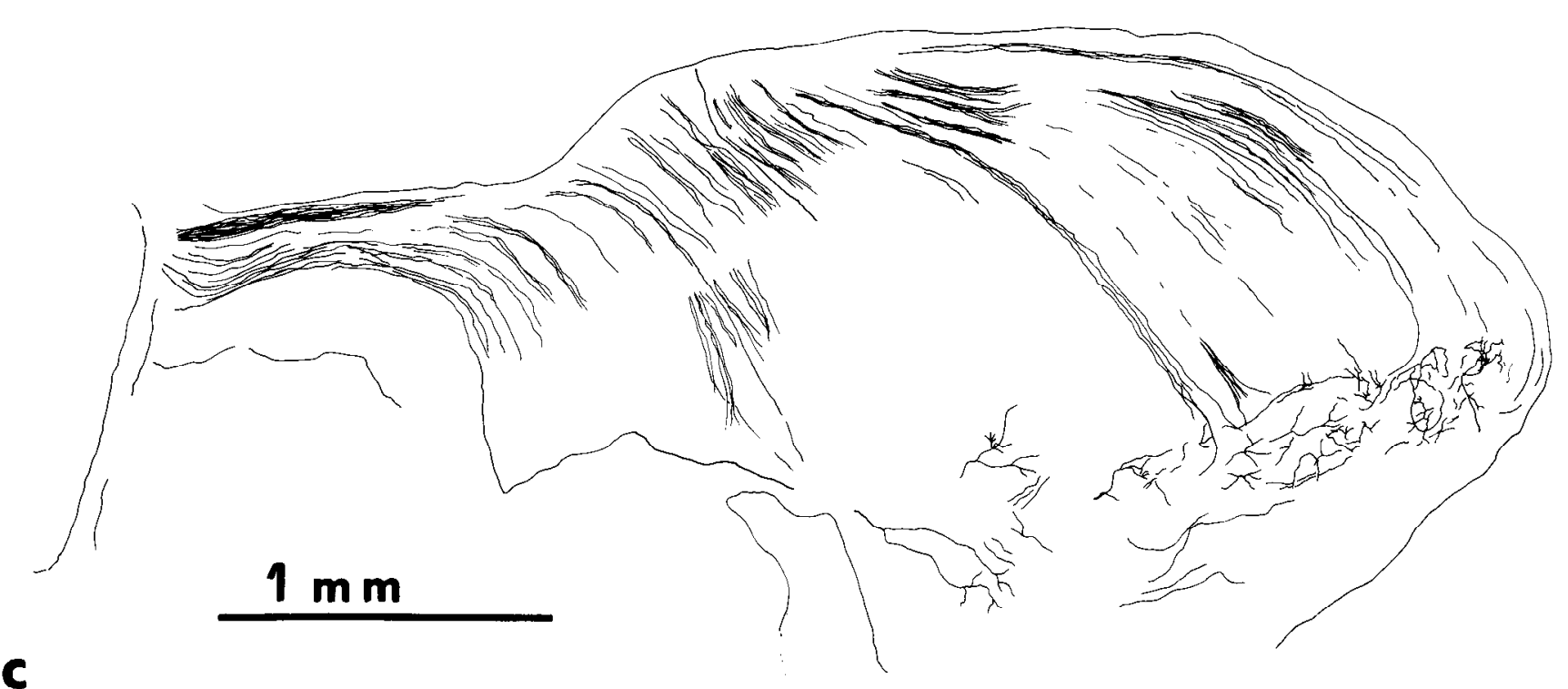

Figure 4. Camera lucida drawings of whole mounted right retina and left tectal lobe following application of $H R P$ to the retina. $R, D, C$, and $V$ are as in Figure $3 . N$, nasal; $T$, temporal. $A$, Whole mounted retina showing labeled sector of axons in ventronasal quadrant. $b$, Whole mounted tectum. The rectangle indicates the region in $c$. $c$, Labeled fascicular axons in the fan-lake array, coursing to the right and downward. The terminal field is a strip in the dorsocaudal quadrant, retinotopic with the labeled sector in $a$. 


\section{a}

D
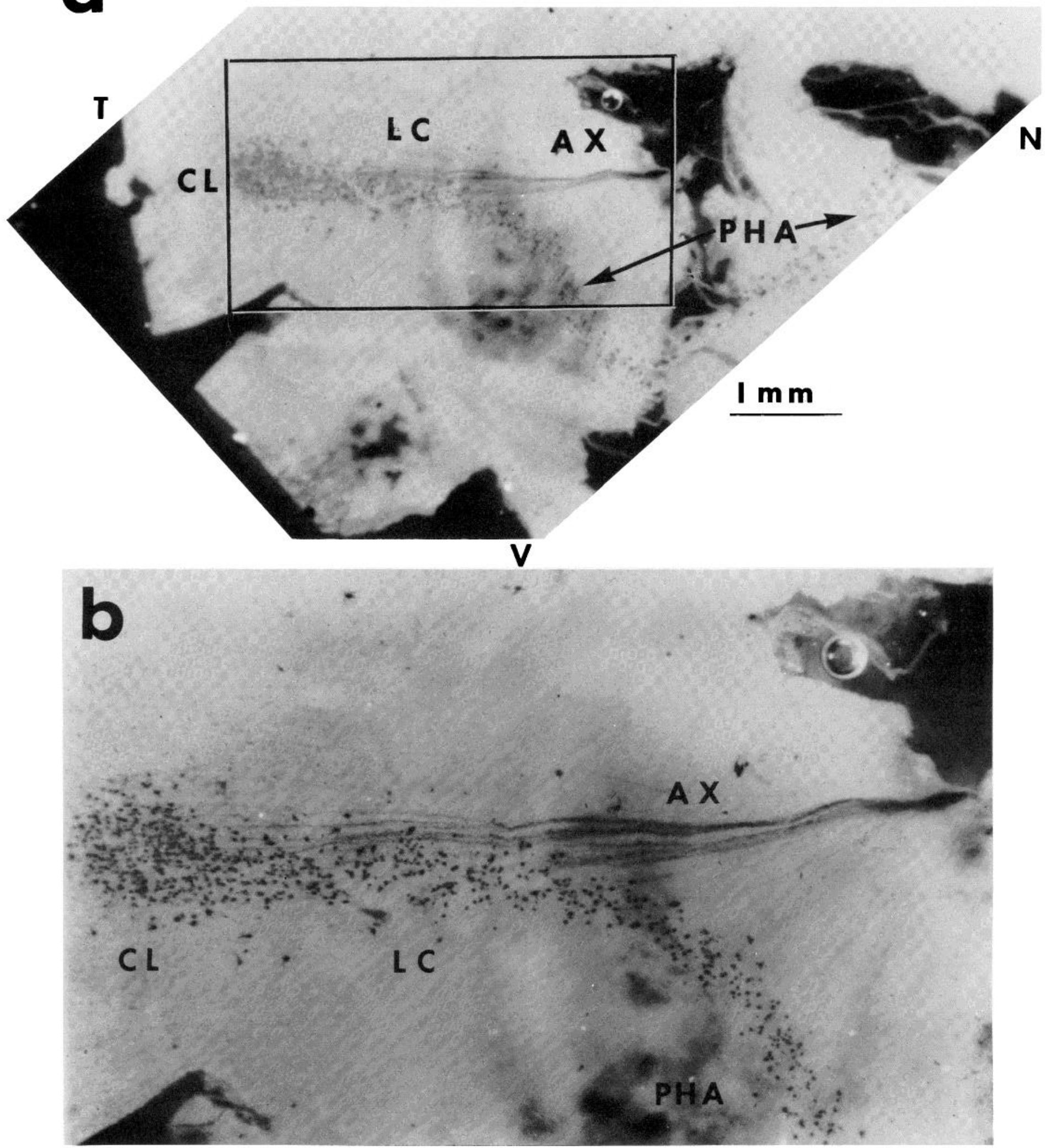

Figure 5. Photomicrographs of retrogradely labeled right retinal whole mount. $a$, This low-magnification view shows the partial half anulus centered on the disk $(P H A)$, the linear connector $(L C)$, and the cluster $(C L)$, which we interpret as the fascicular, extrafascicular, and terminal zones, respectively. Labeled axons $(A X)$ radiate from the optic disk. The rectangle includes the field of $b . b$, The same retina at higher magnification, showing the halo of lightly labeled cells which surrounds the terminal zone. 
label and transport it back to their parent cell bodies. Then we compared the pattern of labeled cells in retina with the predictions from the model.

When HRP was inserted into the dorsomedial portion of the left tectal lobe (at a site similar to $I I$ in Figure $1 b$ ), it produced a sickle-shaped pattern of label in the right ventral retina. An example is shown in Figure 5. The location of the optic disk is evident from the origin of the divergent group of labeled axons. The partial half anulus of labeled cells (fascicular zone) is centered on the disk and extends to the horizontal meridian on the nasal side. The strip of labeled cells (extrafascicular zone) runs roughly parallel to the prominently labeled group of axons and connects the temporal side of the fascicular zone to the terminal zone. The latter is a bulbous cluster of labeled cells in the temporonasal retina, tectotopically related to the site of HRP application.

The surface density of labeled cells was always much greater in the terminal zone than in either of the other two. Although we did not counterstain the retinas and cannot infer what fraction of the ganglion cells were labeled, we know from earlier work that the surface density of ganglion cells is roughly constant over the entire retina in goldfish (Johns and Easter, 1977). The density of labeled cells was always highest in the terminal zone, irrespective of its location. Therefore, a greater fraction of cells labeled through their terminals than through their axons. The terminal zone was also characterized by a halo of very lightly labeled cells (see Fig. $5 b$ ), which we interpret to be a result of diffusion of the label in the synaptic layer.

A total of 16 single HRP applications were made, at the locations shown in the composite drawing in Figure 6 . Four of the sites were so close to one another that they are not shown separately, which explains why there are only 12 circles.

\section{HRP INSERTION SITES}

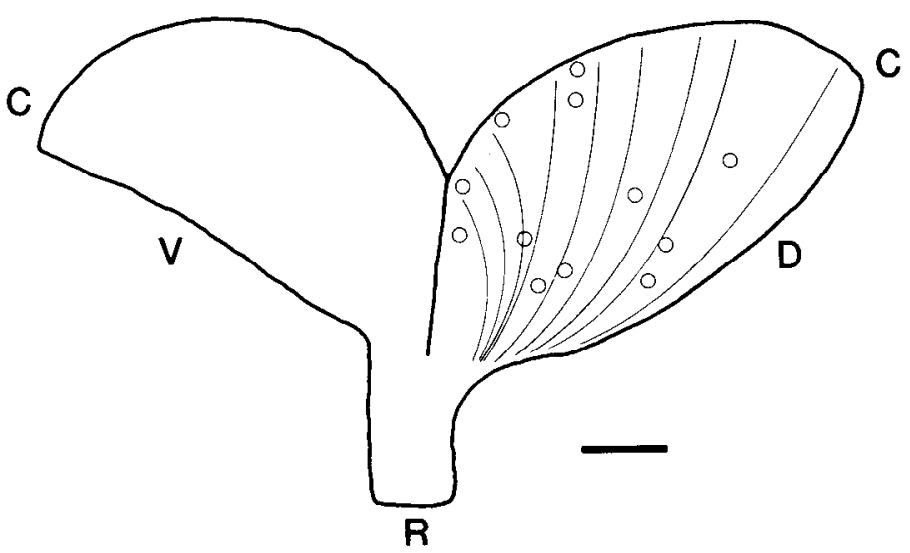

Figure 6. A composite camera lucida drawing (compare Fig. $1 c$ of the preceding paper (Stuermer and Easter, 1984)) in which the circles show the sites of insertion of HRP. Both left and right tecta were labeled; the locations on the left tecta have been shown here in their corresponding locations on the right tectum.
Figure 7 illustrates some of the different patterns of labeling and relates them to the predictions developed in association with Figure 1. All of these experiments were done on fish of 17 to $20 \mathrm{~cm}$ standard length, so their retinas were all about the same size, and the dimensions of the labeled zones may, therefore, be compared directly with one another. Figure $7 a$ shows the results from applications at two sites similar to $I I$ and $I I I$ (Fig. 1, $a$, $d$, and $e$ ). Rostral label (site $I I$ ) produced the sickleshaped pattern with a terminal zone in extreme temporal retina, a long extrafascicular zone, and a fascicular zone relatively close to the disk. The location of the terminal zone was consistent with the retinotopic map. The extrafascicular zone was predicted to be long because this is the oldest part of the tectum and contains the longest extrafascicular axons. The fascicular zone was predicted to lie close to the disk, because the rostral fascicles in the tectum originate from oldest (most central) retina. The angular subtense of the arc is not easily predicted for the rostral fascicles, since it is difficult to know where along their course they were labeled. Caudal label (compare to site $I I I$ in Fig. $1 a$ ) produced only an arc of small angular subtense, restricted to extreme nasal retina and far from the disk. The terminal zone, at the ventralmost edge of the arc, is predictable from the retinotopic map. The absence of a secondary zone was expected because the labeled region of tectum was so young, and extrafascicular axons had not yet grown. The short angular subtense of the arc was expected since the fascicle was labeled near its end.

Figure $7 b$ shows the results of labeling near the tectal equator. All three examples gave very extended patterns, roughly parallel to the horizontal meridian and on a line running through the disk. The partial half anulus in the pattern on the left is unexpected, but it probably resulted from labeling a very rostral fascicle near its origin. (In most rostral tectum the oldest and shortest fascicles lie close to the equator over their entire length.) The short dorsally directed hooks at the nasal ends of the other two are interpreted as short fascicular zones resulting from having labeled near to, but not exactly on, the tectal equator. Of more interest were the lengths and positions of the linear regions. The temporal ends of the strips were predicted to vary according to the rostrality of the label; more rostral labels should have yielded more temporal terminal zones, and they did. The position of the nasal end of the strip was predicted also. The more rostral the label site, the closer to the disk the nasal end should have been. In this case the prediction was not fulfilled so clearly. The most rostral label yielded the closest approach on the nasal side, but the other two approached roughly equally. Finally, the length of the strip was predicted to decrease with more caudal label sites, because shorter extrafascicular axons were labeled in younger tectum; this was fulfilled.

Figure $7 c$ shows patterns from applications to midtectum, at two points with different centroperipheral addresses. The central one resulted in a very compact label with practically no annular region. The peripheral one produced a partial anulus. Note that the angular subtense is very much larger than the one in Figure $7 a$ which 

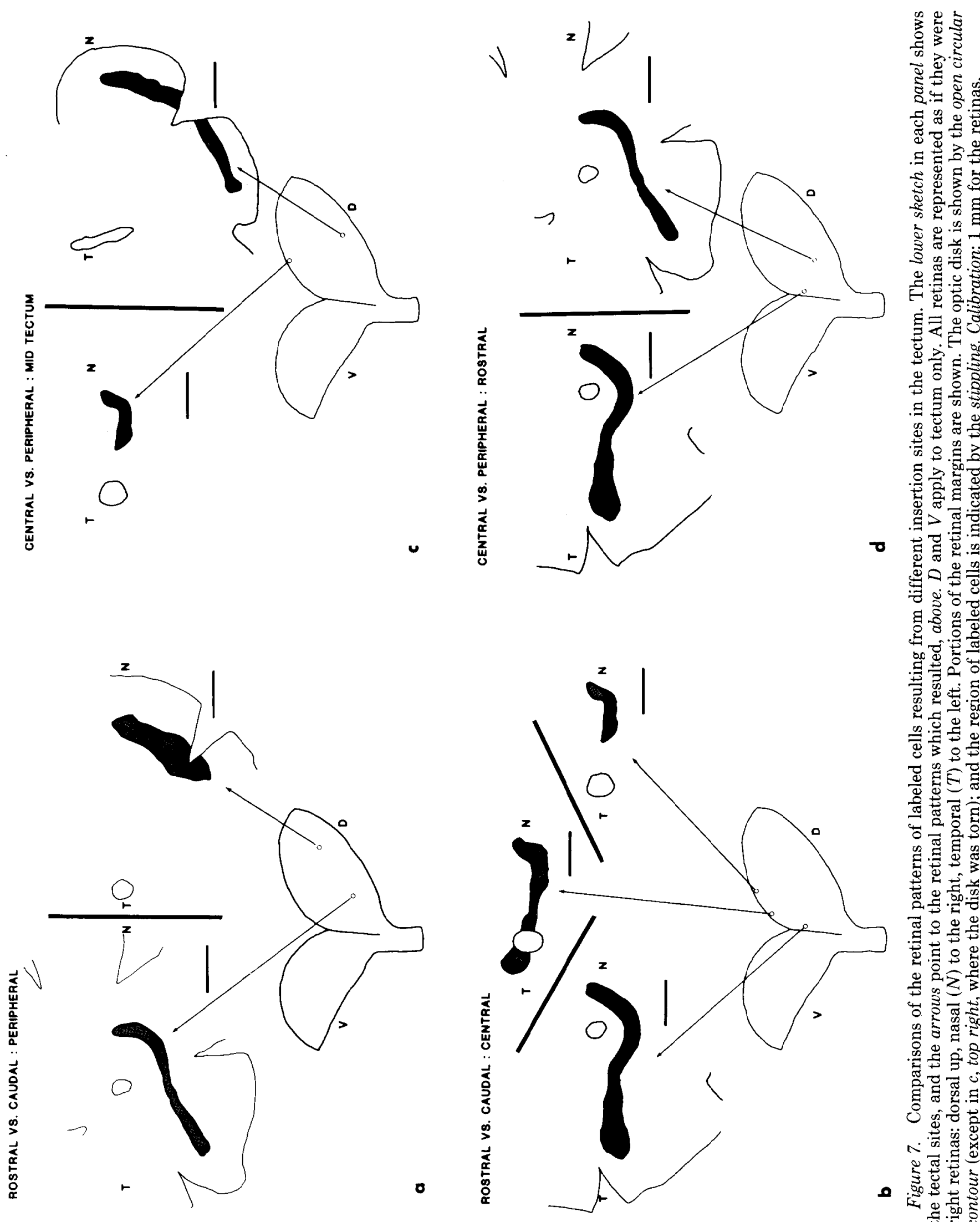

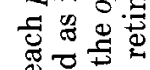

.

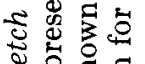

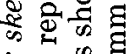

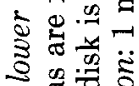

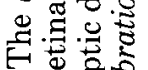

$\dot{1}=\frac{2}{0}$

दे

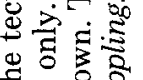

굘.

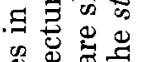

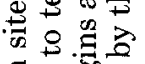

흐룽

产要

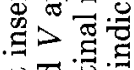

- 可范兽.

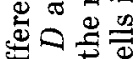

可䓎

घㅇㅇㅇㅇㅇㅇ

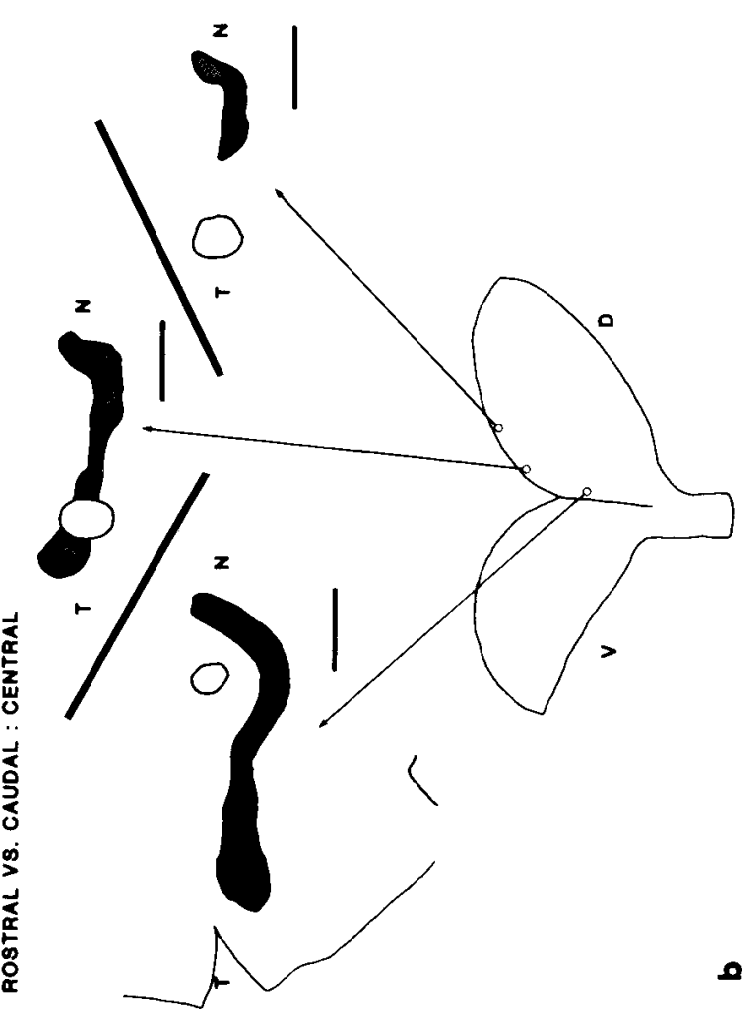

o

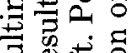

ซึ心

Q⿹

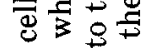

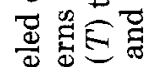

票要

능 응

串. 要

论

造步

폴ㅇ요욯

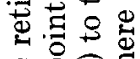

娄交

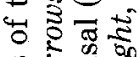

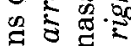

.

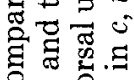

8 si

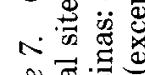

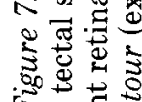

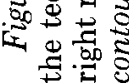


resulted from an equally peripheral, but more caudal, application.

Finally, Figure $7 d$ shows a comparison of two labels given in very rostral tectum but at different centroperipheral positions. The sickle-shaped pattern was produced by both, but the different label sites produced different terminal zones and, therefore, differently oriented extrafascicular zones. The more peripheral (dorsal) label site caught a more peripheral fascicle and, therefore, labeled a more peripheral partial anulus.

These four illustrations show the results of only six label sites (some appear more than once), but nearby sites always gave similar patterns.

In summary, two sets of experimental results, from anterograde and retrograde transport of HRP, fulfilled predictions from our model derived from the hypothesis of shifting terminals.

\section{Discussion}

Evaluation of the principal competing hypothesis. In the preceding paper (Stuermer and Easter, 1984), we offered reasons for doubting the conventional belief that fascicles led directly to the termination sites of the axons in the fascicles. In this paper, we have provided more reasons. If this "direct route hypothesis" were correct, then there would be no need for the extrafascicular segments that we have observed. Morcover, when HRP was inserted, it ought to label a population of ganglion cells restricted to a simple arc, tectotopically related to the labeled fascicle. Our model predicts that this will be so only for the very youngest fascicles, as in the top right of Figure $7 a$. 'The shapes of the labeled zones (the equatorial strips in Fig. $7 b$ and the sickle-shaped patterns in Fig. 7, $a$ and $d$ ) and the presence of nasal retinal axons in rostral tectal fascicles (Fig. $7, a, b$, and $d$ ) are all inconsistent with the "direct route hypothesis."

We have cited Meyer both for his support of the "direct route hypothesis" (Meyer, 1979) and for his suggestion that connections probably shift (Meyer, 1978). Although these two views were not obviously incompatible in 1979, we believe that they are incompatible now, given the recent information about the age-related order of the tectal fascicles.

Relation to other work. Cook and his collaborators have independently carried out some of the same experiments as we, with similar results.

Cook (1983) made stab wounds in the dorsomedial tectum of goldfish, applied HRP at the lesion, and found that the labeled ganglion cells occupied a quarter anulus in ventral retina. This is similar to the pattern seen in our Figure $7 a$, following caudal label. Although he reports no sickle-shaped patterns or equatorial strips, as we did, he apparently did not vary the site of HRP application. Therefore, our results are consistent with his, assuming that he labeled in relatively young tectum.

Cook et al. (1983) labeled axons in the optic nerve with HRP and traced them through the tectum. They observed caudally directed extrafascicular axons deep to SO, in complete agreement with our results (Figs. 3 and 4). Moreover, they measured these axons individually and found that those which originated more rostrally were longer, as predicted.
Shifting terminals. In any attempt to demonstrate shifting terminals, it is necessary to have a marker showing where the terminals were at an earlier time, so that this may be compared with their current location. In the approach of Scott and Lázár (1976), Jacobson (1977), Gaze et al. (1979), and Reh and ConstantinePaton (1984), the marker was the boundary of labeled nuclei produced by an earlier injection of radioactive thymidine. All terminals were known to have been rostral to this boundary earlier but were caudal to it later; hence, the inference that they had moved.

Fraser (1983) used an electrolytic lesion to mark where ganglion cells from central retina had projected earlier, and compared this with a later lesion in the same animal, which marked the new projection site of these same cells. They were separated by $150 \mu \mathrm{m}$. The logic of this experimental approach is clear and simple, but the description of the "fiber optic mapping" technique is not detailed enough to permit an estimate of its accuracy. The technique and its limitations will have to be described more completely before the conclusion can be considered justified.

In our work, we have used the fascicle in SO as the permanent marker. Earlier work (Easter et al., 1981; Stuermer and Easter, 1982, 1984) has shown that the new axons grow along the edge of the tectum - thus creating the newest and the most peripheral fascicleand terminate nearby. This fascicle later becomes partially enveloped by new tectal tissue. The position of the fascicle, with respect to the radially oriented glia and neurons, resembles that of a rope in a field of corn. If the rope lies below the tops of the corn plants, then it cannot slide laterally without knocking down the plants. Similarly, once the fascicle is in place and bounded by a population of radially directed cells, it cannot acquire new neighbors without cutting through the original ones. We assume that the fascicles have not done so. Indeed, it is difficult to interpret our results in any other way. Although a fascicle's absolute position with respect to, say, the rostral pole of the tectum may change as a result of tectal enlargement due to stretch (Raymond and Easter, 1983), the vicinage of cells remains constant. Therefore, the existence of extrafascicular axons and the details of their tectal courses and retinal origins provide strong evidence in support of the hypothesis of shifting terminals in general and of our model in particular.

"Terminals" versus "connections." The original formulation of what has been called here the "hypothesis of shifting terminals" was slightly different-namely, the "hypothesis of sliding connections" (Gaze et al., 1974). We prefer "shifting" to "sliding" because it is less specific and connotes nothing about the mechanism of movement. The word "terminals" was substituted for "connections" because most previous work, and all of the work in this paper, dealt with the terminal arbors of retinal ganglion cells, and no claim for synaptic connectivity was made. However, it is widely assumed that the terminal arbor includes functional presynaptic terminals, and the implied synaptic lability is the most novel-and in many ways revolutionary-aspect of the hypothesis. We close here by reminding the reader that there are three independent experiments which support the con- 
tention that, in Xenopus, synaptic connections are made and broken during normal growth. First, Chung et al. (1974) showed electrophysiologically that stimulation of the optic nerve produced postsynaptic activity early in development (stage $\mathbf{4 8}$ and later). Therefore, functional contacts between retina and tectum are formed early, before the retina and the tectum have stopped growing. Second, Longley (1978) demonstrated retinal presynaptic terminals in retinotopic positions in tectum by stage 51. Therefore, at least some of the presynaptic terminals are initially in sites that they do not occupy later. Third, Gaze et al. (1979) searched electron microscopically for degenerating terminals in larval Xenopus tectum and found them to be most numerous in rostral tectum, where the putative abandoned terminals were predicted to be.

We believe that these results support the idea that where axons arborize, they almost certainly form synaptic contacts. But we emphasize that the hypothetical shift of the terminals, without specifying connections, is now very strongly indicated in both fish and amphibians.

\section{References}

Attardi, D. G., and R. W. Sperry (1963) Preferential selection of central pathways by regenerating optic fibers. Exp. Neurol. 7: 46-64.

Chung, S. H., M. J. Keating, and T. V. P. Bliss (1974) Functional synaptic relations during the development of the retino-tectal projection in amphibians. Proc. R. Soc. Lond. Biol. 187: 449-459.

Cook, J. E. (1983) Tectal paths of regenerated optic axons in the goldfish: Evidence from retrograde labeling with horseradish peroxidase. Exp. Brain Res. 51: 433-442.

Cook, J. E., E. C. C. Rankin, and H. P. Stevens (1983) A pattern of optic axons in the normal goldfish tectum consistent with the caudal migration of optic terminals during development. Exp. Brain Res. 52: 147-151.

Easter, S. S., Jr., and C. A. O. Stuermer (1982) Evidence for naturally occurring movements of retinotectal terminals in goldfish. Soc. Neurosci. Abstr. 8: 745.

Easter, S. S., Jr., and C. A. O. Stuermer (1983) Establishment and maintenance of the retinotectal projection in goldfish. Invest. Ophthalmol. Vis. Sci. Suppl. 24: 8.

Easter, S. S., Jr., A. C. Rusoff, and P. E. Kish (1981) The growth and organization of the optic nerve and tract in juvenile and adult goldfish. J. Neurosci. 1: 793-811.

Fraser, S. E. (1983) Fiber optic mapping of the Xenopus visual system: Shift of the retinotectal projection during development. Dev. Biol. 95: 505-511.

Fujisawa, H., K. Watanabe, N. Tani, and Y. Ibata (1981) Retinotopic analysis of fiber pathways in amphibians. 1. The adult newt Cynops pyrrhogaster. Brain Res. 206: 9-20.

Gaze, R. M., M. J. Keating, and S. H. Chung (1974) The evolution of the retinotectal map during development in Xenopus. Proc. R. Soc. Lond. Biol. 185: 301-330.

Gaze, R. M., M. J. Keating, A. Ostberg, and S. H. Chung (1979) The relationship between retinal and tectal growth in larval Xenopus: Implications for the development of the retinotectal projection. J. Embryol. Exp. Morphol. 53: 103-143.
Hoskins, S. G., and P. Grobstein (1982) Retinal histogenesis and the development of the ipsilateral retinothalamic projection in Xenopus. Soc. Neurosci. Abstr. 8: 513.

Jacobson, M. (1976) Histogenesis of retina in the clawed frog with implications for the pattern of development of retinotectal connections. Brain Res. 103: 541-545.

Jacobson, M. (1977) Mapping the developing retinotectal projection in frog tadpoles by a double label autoradiographic technique. Brain Res. 127: 55-67.

Johns, P. R. (1977) Growth of the adult goldfish eye. III. Source of the new retinal cells. J. Comp. Neurol. 176: 343-358.

Johns, P. R., and S. S. Easter, Jr. (1977) Growth of the adult goldfish eye. II. Increase in retinal cell number. J. Comp. Neurol. 176: 331-342.

Kirsche, W. (1967) Uber postembryonale Matrixzonen in $\mathrm{Ge}$ hirn verschiedener Vertebraten und deren Beziehung zur Hirnbauplanlehre. Z. Mikrosk. Anat. Forsch. 77: 313-406.

Longley, A. (1978) Anatomical mapping of retino-tectal connections in developing and metamorphosed Xenopus: Evidence for changing connections. J. Embryol. Exp. Morphol. 45: 249-270.

Meyer, R. L. (1977) Eye-in-water electrophysiological mapping of goldfish with and without tectal lesions. Exp. Neurol. 56: $23-41$.

Meyer, R. L. (1978) Evidence from thymidine labeling for continuing growth of retina and tectum in juvenile goldfish. Exp. Neurol. 59: 99-111.

Meyer, R. L. (1979) "Extra" optic fibers exclude normal fibers from tectal regions in goldfish. J. Comp. Neurol. 183: 883902.

Müller, H. (1952) Bau and Wachstum der Netzhaut des Guppy (Lebistes reticulatus). Zool. Jb. 63: 275-324.

Raymond, P. A., and S. S. Easter, Jr. (1983) Postembryonic growth of the optic tectum in goldfish. I. Location of germinal cells and number of neurons produced. J. Neurosci. 3: 10771091.

Reh, T. A., and M. Constantine-Paton (1984) Retinal ganglion cell terminals change their projection sites during larval development of Rana pipiens. J. Neurosci. 4: 442-457.

Schmidt, J. T., C. M. Cicerone, and S. S. Easter, Jr. (1978) Expansion of the half retinal projection to the tectum in goldfish. An electrophysiological and anatomical study. J. Comp. Neurol. 177: 257-277.

Scott, T. M., and G. Lázár (1976) An investigation into the hypothesis of shifting neuronal relationships during development. J. Anat. 121: 485-496.

Straznicky, K., and R. M. Gaze (1971) The growth of the retina in Xenopus laevis: An autoradiographic study. J. Embryol. Exp. Morphol. 26: 67-79.

Straznicky, K., and R. M. Gaze (1972) The development of the tectum in Xenopus laevis: An autoradiographic study. J. Embryol. Exp. Morphol. 28: 87-115.

Stuermer, C. A. O., and S. S. Easter, Jr. (1982) Growth-related order of optic axons in goldfish tectum. Soc. Neurosci. Abstr. 8: 451 .

Stuermer, C. A. O., and S. S. Easter, Jr. (1983) Goldfish retinal axons: Intratectal pathways to their sites of termination. Invest. Ophthalmol. Vis. Sci. Suppl. 24: 8.

Stuermer, C. A. O., and S. S. Easter, Jr. (1984) Rules of order in the retinotectal fascicles of goldfish. J. Neurosci. 4: 10451051 . 